\title{
Chronic stage of Marchiafava-Bignami disease
}

\section{Fase crônica da doença de Marchiafava-Bignami}

Leandro Tavares Lucato ${ }^{1}$, Fernando Freua ${ }^{1,2}$, Fernando Kok ${ }^{1}$

Marchiafava-Bignami disease, first described in 1903, is a rare condition characterized by demyelination of the corpus callosum seen in patients with chronic alcoholism or nutritional susceptibility. Magnetic resonance imaging (MRI) is currently the most sensitive diagnostic tool (Figure). A 24-year-old man, with a background of high level of alcohol abuse since he was 12, presented since last year behavioral and psychotic clinical manifestations characterized by elaborated visual and auditory delusions.
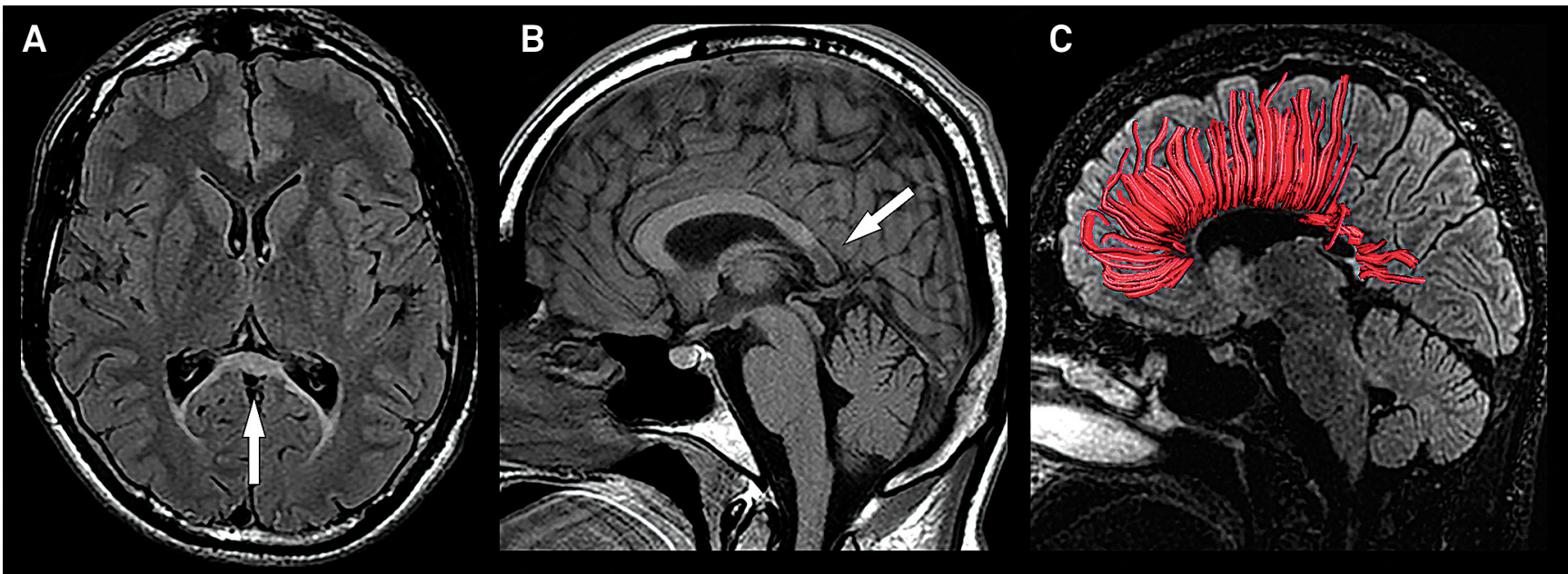

Figure. Axial FLAIR image (Panel A, arrow) shows hyperintensity in the splenium of the corpus callosum. Sagittal T1-weighted image (Panel B, arrow) demonstrates the focal nature of this lesion. Three-dimensional fiber tracking of corpus callosum coregistered onto a parasagittal FLAIR image (Panel C) discloses a substantial decrease in fibers crossing through the splenium.

1. Marchiafava E, Bignami A. Sopra un alterazione del corpo calloso osservata in soggetti alcoolisti. Riv Patol Nerv Ment. 1903;8:544-9.
2. Hillbom M, Saloheimo P, Fujioka S, Wszolek ZK, Juvela S, Leone MA. Diagnosis and management of Marchiafava-Bignami desease: a review of CT/MRI confirmed cases. J Neurol Neurosurg Psychiatry. 2014;85(2):168-73. doi:10.1136/jnnp-2013-305979

\footnotetext{
'Hospital das Clínicas da Universidade de São Paulo, Sao Paulo SP, Brazil; ${ }^{2}$ Hospital Samaritano de São Paulo, Sao Paulo SP, Brazil.

Correspondence: Fernando Freua; Rua Conselheiro Brotero, 1505 / Cj 41; 01232-010 São Paulo SP, Brasil; E-mail: fernando.freua@gmail.com Conflict of interest: There is no conflict of interest to declare.

Received 17 April 2015; Accepted 08 May 2015.
} 